\title{
Impact of Vacuum-Assisted Venous Drainage on Forward Flow in Simulated Pediatric Cardiopulmonary Bypass Circuits Utilizing a Centrifugal Arterial Pump Head
}

Daniel Peres Guimarães ${ }^{1}$, MD; Luiz Fernando Caneo ${ }^{1}$, MD, PhD; Gregory Matte ${ }^{2}$, CCP, LP, FPP; Luciana P. Carletto ${ }^{1}$, CCP; Valéria Camargo Policarpo ${ }^{1}$, CCP; Ana Vitória C. X. Castro ${ }^{1}$, CCP; Matheus H. C. Miranda', CCP; Priscila S. Costa $^{1}$, CCP; Marcelo B. Jatene ${ }^{1}$, MD, PhD; Idagene Cestari ${ }^{1}$, PhD; Fabio B. Jatene ${ }^{1}$, MD, PhD

DOI: $10.21470 / 1678-9741-2019-0311$

\begin{abstract}
Objective: To analyze the impact of vacuum-assisted venous drainage (VAVD) on arterial pump flow in a simulated pediatric cardiopulmonary bypass circuit utilizing a centrifugal pump (CP) with an external arterial filter.

Methods: The simulation circuit consisted of a Quadrox-I Pediatric oxygenator, a Rotaflow CP (Maquet Cardiopulmonary AG, Rastatt, Germany), and a custom pediatric tubing set primed with Lactated Ringer's solution and packed red blood cells. Venous line pressure, reservoir pressure, and arterial flow were measured with VAVD turned off to record baseline values. Four other conditions were tested with progressively higher vacuum pressures $(-20,-40$, -60 , and $-80 \mathrm{mmHg}$ ) applied to the baseline cardiotomy pressure. An arterial filter was placed into the circuit and arterial flow was measured with the purge line in both open and closed positions.
\end{abstract}

These trials were repeated at set arterial flow rates of 1500, 2000, and $2500 \mathrm{~mL} / \mathrm{min}$.

Results: The use of progressively higher vacuum caused a reduction in effective arterial flow from $1490 \pm 0.00$ to $590 \pm 0.00$, from $2020 \pm 0.01$ to $1220 \pm 0.00$, and from $2490 \pm 0.0$ to $1830 \pm 0.01 \mathrm{~mL} / \mathrm{min}$. Effective forward flow decreased with increased levels of VAVD.

Conclusion: The use of VAVD reduces arterial flow when a CP is used as the main arterial pump. The reduction in the forward arterial flow increases as the vacuum level increases. The loss of forward flow is further reduced when the arterial filter purge line is kept in the recommended open position.

An independent flow probe is essential to monitor pump flow during cardiopulmonary bypass.

Keywords: Congenital Heart Disease. Cardiopulmonary Bypass. Child. Vacuum. Drainage. Pressure. Erythrocytes.

\begin{tabular}{ll}
\hline Abbreviations, acronyms \& symbols \\
\hline CP & $=$ Centrifugal pump \\
CPB & $=$ Cardiopulmonary bypass \\
CVR & $=$ Cardiotomy venous reservoir \\
GME & $=$ Gaseous microemboli \\
HLMs & $=$ Heart-lung machines \\
KAVD & $=$ Kinetic-assisted venous drainage \\
RP & $=$ Roller pump \\
RPM & $=$ Rotations per minute \\
VAVD & $=$ Vacuum-assisted venous drainage \\
VLP & $=$ Venous limb pressure
\end{tabular}

${ }^{1}$ Cardiovascular Surgery Division, Instituto do Coração do Hospital das Clínicas da Faculdade de Medicina da Universidade de São Paulo (InCor-HC-FMUSP), São Paulo, SP, Brazil.

2Department of Cardiac Surgery, Boston Children's Hospital, Boston, MA, USA.

This study was carried out at the Cardiovascular Surgery Division, Instituto do Coração do Hospital das Clínicas da Faculdade de Medicina da Universidade de São Paulo (InCor-HC-FMUSP), São Paulo, SP, Brazil.

\section{INTRODUCTION}

Traditional gravity siphon drainage with small size cannulae and tubings may provide insufficient blood return to the cardiotomy reservoir and compromise effective forward flow and tissue perfusion ${ }^{[1,2]}$. Assisted venous drainage techniques such as kinetic-assisted venous drainage (KAVD) and vacuum-assisted venous drainage (VAVD) are used to improve venous return ${ }^{[3]}$. KAVD uses a centrifugal pump (CP) placed in the venous line to generate negative venous line pressure while VAVD involves application of a constant vacuum pressure to the airtight cardiotomy venous reservoir (CVR). VAVD is largely used not only in minimally invasive surgery, but also commonly in pediatric cardiac surgery, with small circuits and/or small cannulae ${ }^{[3]}$.

\footnotetext{
Correspondence Address:

Daniel Peres Guimarães

(iD) https://orcid.org/0000-0002-3198-9101

Departamento de Cirurgia Cardiovascular, Instituto do Coração da Faculdade de Medicina da Universidade de São Paulo

Av. Dr. Enéas Carvalho de Aguiar, 44 - Cerqueira César, São Paulo, SP, Brazil

Zip Code: 05403-900

E-mail: daniel.pgmrs@gmail.com
} 
Roller pump (RP) and CP are the two main arterial pump designs used during cardiopulmonary bypass (CPB). CP employs the mechanical principle of a constrained vortex created by rotating nested cones or vane impellers. This design eliminates circuit tubing compression and mitigates shear stress-induced cellular responses and complements activation, which potentially improves hemostasis ${ }^{[4,5]}$. This lack of occlusion also reduces local areas of negative pressure cavitation and gaseous microemboli (GME) transmission ${ }^{[6]}$. Some authors have concluded that the use of CP may reduce CPB-related morbidity and decrease the cost of cardiac surgery ${ }^{[7]}$. The use of $\mathrm{CP}$ rather than RP during regular CPB may be justified based on the theoretical advantages of CPs over RPs ${ }^{[5-7]}$.

Until now, to the best of our knowledge, there is no evidence-based difference in hematologic parameters and clinical outcomes with the use of a CP or RP as the main arterial pump in adult cardiac surgery ${ }^{[8]}$. Despite no superior advantage of CPs over RPs, CPs are used in 51\% of CPB cases in Brazil, in both pediatric and adult patients ${ }^{[9]}$. There are centers using CPs in almost $100 \%$ of their cases, which is justified only by their observational outcomes. Interestingly, VAVD is routinely used in almost every case, utilizing a CP as the arterial pump head. $\mathrm{CP}$ is non-occlusive and could facilitate bubble transgression when used in the arterial position associated with VAVD. Jegger et al. ${ }^{[10]}$ demonstrated that VAVD is a safe technique as long as the perfusionist stops the vacuum when the arterial pump is no longer in use. That group also concluded that the use of RP is preferred in the arterial position ${ }^{[10]}$. Another potential problem associated with the use of CPs and VAVD is the influence of vacuum on the effective forward flow, either due to increased arterial filter purge flow or a reduced CP output with VAVD applied to the CVR. These concerns mean that perfusionists must monitor forward flow with a flow probe distal to any potential circuit shunts.

This study aimed to evaluate the effective forward flow using a CP as the arterial pump associated with VAVD, with and without an external arterial line filter purge in use, in a simulated pediatric CPB circuit.

\section{METHODS}

\section{Experimental Circuits}

The experimental circuit included a pediatric QuadroxiD oxygenator without an integrated arterial filter (Maquet Cardiopulmonary AG, Rastatt, Germany), a Rotaflow CP as the arterial pump, an 18Fr straight tip arterial cannula (Medtronic, Inc, Minneapolis, MN, USA), an HCU-20 heater cooler system (Maquet Cardiopulmonary AG, Rastatt, Germany), a vacuum regulator (Braile Biomedica, Brazil), and a pediatric arterial line filter (Braile Biomedica, Brazil), as shown in Figure 1. This filter was added into the arterial arm of the circuit with an $8 \mathrm{~mm}$ inner diameter tubing purge line.

The pseudopatient consisted of a $2000 \mathrm{ml}$ capacity hardshell reservoir (Maquet Cardiopulmonary AG, Rastatt, Germany). This reservoir level was located $80 \mathrm{~cm}$ above the CVR and was connected with $3 / 8^{\prime \prime}$ venous tubing (Figure 1). Venous limb lengths were standardized to $120 \mathrm{~cm}$. The arterial pump consisted of a Rotaflow CP for all test conditions connected to $150 \mathrm{~cm}$ of $1 / 4^{\prime \prime}$ ID tubing.

\section{Experimental Design}

The experimental circuit was primed with Lactated Ringer's solution (Baxter, São Paulo, Brazil) followed by heparinized human packed red blood cells to achieve a circuit hematocrit of 30\%. The pseudopatient's volume was held constant at $300 \mathrm{~mL}$ using a Hoffman clamp just before the venous line. Pseudopatient's pressure (post-arterial cannula pressure) was maintained at 50 $\mathrm{mmHg}$ at the beginning of the study using another Hoffman clamp after the arterial cannula. The oxygenator venous reservoir level was kept at a minimum of $200 \mathrm{~mL}$ during all experiments. A vacuum regulator (Nipro Corporation do Brasil, SP, Brazil) controlled VAVD pressures.

Venous limb pressure (VLP), CVR pressure, and arterial flow were recorded in five different conditions: atmospheric pressure (vacuum off) and four different vacuum levels (aiming a negative pressure of $-20,-40,-60$, and $-80 \mathrm{mmHg}$ - conditions A to E), Tables 1 and 2. Initial pump flow rate was adjusted to 1500,2000 , and $2500 \mathrm{~mL} / \mathrm{min}$ with purge line clamp closed. The experiment was conducted with the purge line both open and closed to compare the deviated flow through the arterial line filter purge line.

\section{Data Acquisition}

Two Transonic ultrasound flow probes (Transonic Systems, Inc., Ithaca, NY, USA) were used for each set of test conditions in setup I. One flow probe was located before arterial line filter and the other after the filter, as shown in Figure 1.

Three Edwards TruWave disposable pressure transducers (Edwards Lifesciences Corp., Irvine, CA, USA) were placed. The first was located at the beginning of the venous limb (P1), the second at the CVR (P2), and the third at the post-arterial cannula site (P3). Pressure transducers were connected to CPB-100 pressure monitors (Bioengineering Division, InCor-HC-FMUSP, São Paulo, Brazil). Pressure monitor and flowmeter outputs were connected to a DataQ DI-710 data acquisition device (DataQ, Akron, OH, USA) and then connected to a computer via universal serial bus port. WinDaq data acquisitions software (DataQ, Akron, OH, USA) was used to record real-time data at 1000 samples per second per channel. A 30 s segment of pressure and flow waveforms was recorded for each set of variables.

\section{Purge Line Shunt Flow Calculation}

The purge line shunt flow was calculated in setup II with the purge line both open and closed. Purge line shunt flow was calculated from measured flow rates at pre-oxygenator and prearterial cannula locations: purge line shunt flow $=$ pre-arterial filter flow - post-arterial filter (pre-arterial cannula) flow.

\section{Statistical Analysis}

The variables are presented in mean and standard deviation. One-way ANOVA-repeated measures were used to compare total pressure drop between venous reservoir levels $(1500 \mathrm{~mL}$, $2000 \mathrm{~mL}$, and $2500 \mathrm{~mL}$ ) and VAVD levels $(0,-20,-40,-60$, and 
-80). Tukey's multiple comparisons test was done to identify the difference between the variables studied. The statistical significance threshold was a $P$-value $<0.05$. All analyses were performed using GraphPad Prism software (San Diego, CA, USA) for Mac version 6.0 (Microsoft Corporation, Redmond, WA, USA).

\section{RESULTS}

The mean VLP (P1), mean venous reservoir pressure (P2), effective forward flow, and purge line shunt flow are shown in Table 1, with the arterial line filter purge turned off. Table 2 shows the same experimental conditions but with the arterial line filter purge in the clinically recommended open position. Effective forward flow is negatively impacted with increasing levels of VAVD, with and without the arterial line filter purge in the open position, as shown in Tables 1 and 2. The use of the highest experimental VAVD setting caused a significant $(P<0.0001)$ reduction of the arterial flow from $1490 \pm 0.00 \mathrm{~mL} /$ min to $590 \pm 0.00 \mathrm{~mL} / \mathrm{min}$, from $2020 \pm 0.01 \mathrm{~mL} / \mathrm{min}$ to $1220 \pm 0.00$ $\mathrm{mL} / \mathrm{min}$, and from $2490 \pm 0.0 \mathrm{~mL} / \mathrm{min}$ to $1830 \pm 0.01 \mathrm{~mL} / \mathrm{min}$, as shown in Figure 2, graphics I and II. A significant $(P<0.0001)$ and progressive decrease in effective forward flow was also observed when the purge line was open, as shown in Figure 3, graphic III. Shunt flow with the arterial filter purge line open progressively increased $(P=0.0003)$ as the vacuum applied to the venous reservoir also increased. Purge line shunt flow was proportionally higher with lower pump flows and increasing levels of VAVD, ranging from $80 \%$ of overall flow with the arterial flow set at 1500 $\mathrm{mL} / \mathrm{min}$ with $-80 \mathrm{mmHg}$ of VAVD to $34 \%$ of overall flow with the arterial flow set at $2500 \mathrm{~mL} / \mathrm{min}$ with $-80 \mathrm{mmHg}$, as shown in Figure 3, graphic IV $(P=0.01)$.

\section{DISCUSSION}

VAVD is a common technique used in many cardiac surgery centers worldwide ${ }^{[11-13]}$. Its use seeks to significantly improve venous drainage during CPB surgeries, especially when smaller inner diameter cannulas are used or with minimally invasive surgery ${ }^{[14,15]}$. Applying vacuum to a sealed venous reservoir improves venous drainage, but it also impacts CP output when one is used in the arterial position. Increased VAVD levels require the clinician to increase the CP rotations per minute (RPM) to compensate ${ }^{[16]}$. We found a significant decrease in effective forward flow from 1490 to $590 \mathrm{~mL} / \mathrm{min}$, from 2020 to $1220 \mathrm{~mL} /$ $\mathrm{min}$, and from 2490 to $1830 \mathrm{~mL} / \mathrm{min}$ with the application of -80 $\mathrm{mmHg}$ of VAVD in our experimental circuit. With the arterial filter purge line open or with any shunt line, such as a passive hemoconcentrator, increasing VAVD levels result in increased shunt flow, which steals effective forward flow for the patient ${ }^{[16]}$. Therefore, using a flow probe is essential for patient safety, particularly with external arterial line filters and a CP in the arterial position ${ }^{[16]}$.

The main finding in this experiment was that effective forward flow is compromised both with the use of a centrifugal arterial pump head and an open external arterial line filter purge and that these effects are magnified with increasing levels of VAVD. This is of concern for clinical practice in Brazil, as many centers use a centrifugal arterial pump head without monitoring effective forward flow with an independent flow probe as we did in this experiment.

Brazil has a long history of creating innovative products for cardiovascular surgery, including domestically produced heart-lung machines (HLMs), oxygenators, and other perfusion products. While Brazil maintains an environment of innovation, there are areas of clinical practice where outdated technologies are still clinically employed ${ }^{[17]}$. Some perfusionists and surgeons consider Brazilian non-servo-controlled HLMs unsafe for pediatric perfusion, especially when low flow is needed. Some also prefer using an imported CP as the main arterial pump. For them, using CP as the main pump, despite any scientific data, is related to safer and better outcomes.

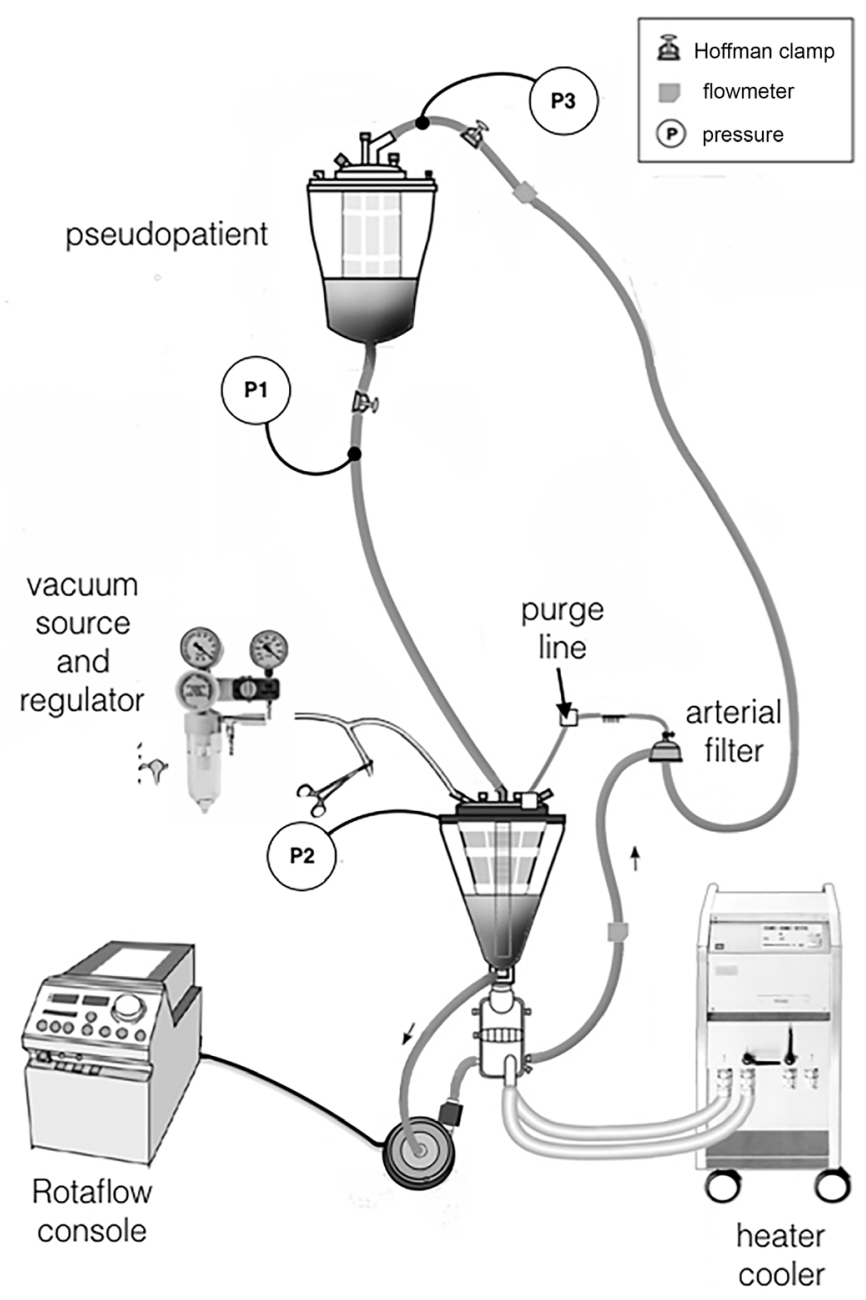

Fig. 1 - The circuit employed in this study simulating a pediatric cardiopulmonary bypass with a centrifugal pump as the main pump. Two Hoffman clamps were used to control the venous drainage and the post-cannula pressure (adjusted to $50 \mathrm{mmHg}$ at the beginning of each range of flow - 1500, 2000, and 2500mL). Two flow probes were placed into the arterial line before and after the arterial filter. Pressure was measured in three sites: at the venous limb close to the pseudopatient (P1), at the cardiotomy venous reservoir (P2), and post-arterial cannula site (P3). 
Table 1. Mean venous limb pressure (P1), mean venous reservoir pressure (P2), and arterial line flow (forward flow) measured at baseline flow of 1500, 2000, and $2500 \mathrm{~mL} / \mathrm{min}$ with vacuum off and increments of vacuum-assisted venous drainage levels (-20, -40 , -60 , and -80; conditions A to E) keeping the purge line closed.

\begin{tabular}{|c|c|c|c|c|}
\hline Adjusted flow & Condition & $\begin{array}{l}\text { P1 venous limb } \\
\text { pressure }(\mathrm{mmHg})\end{array}$ & $\begin{array}{l}\text { P2 venous reservoir } \\
\text { pressure }(\mathrm{mmHg})\end{array}$ & $\begin{array}{l}\text { Effective forwarc } \\
\text { flow (mL/min) }\end{array}$ \\
\hline \multirow{5}{*}{$1500 \mathrm{ml} / \mathrm{min}$} & A & $-27.67 \pm 0.12$ & $-0.73 \pm 0.00$ & $1490 \pm 0.00$ \\
\hline & B & $-50.22 \pm 0.35$ & $-21.47 \pm 0.49$ & $1300 \pm 0.00$ \\
\hline & C & $-67.73 \pm 0.11$ & $-39.29 \pm 0.08$ & $1100 \pm 0.00$ \\
\hline & D & $-88.01 \pm 0.28$ & $-58.70 \pm 0.25$ & $880 \pm 0.00$ \\
\hline & $E$ & $-112.25 \pm 0.10$ & $-79.72 \pm 0.13$ & $590 \pm 0.00$ \\
\hline \multirow{5}{*}{$2000 \mathrm{ml} / \mathrm{min}$} & A & $-26.40 \pm 1.43$ & $-1.24 \pm 1.38$ & $2020 \pm 0.01$ \\
\hline & $B$ & $-51.40 \pm 1.92$ & $-24.88 \pm 1.59$ & $1810 \pm 0.02$ \\
\hline & C & $-66.08 \pm 0.38$ & $-37.79 \pm 0.44$ & $1640 \pm 0.01$ \\
\hline & $\mathrm{D}$ & $-87.03 \pm 0.20$ & $-58.31 \pm 0.10$ & $1440 \pm 0.00$ \\
\hline & $E$ & $-109.59 \pm 0.19$ & $-80.65 \pm 0.10$ & $1220 \pm 0.00$ \\
\hline \multirow{5}{*}{$2500 \mathrm{ml} / \mathrm{min}$} & A & $-25.32 \pm 0.09$ & $-1.37 \pm 0.12$ & $2490 \pm 0.00$ \\
\hline & $B$ & $-41.61 \pm 2.42$ & $-19.62 \pm 1.39$ & $2370 \pm 0.02$ \\
\hline & $C$ & $-64.32 \pm 0.38$ & $-38.40 \pm 0.35$ & $2180 \pm 0.01$ \\
\hline & $D$ & $-88.99 \pm 0.08$ & $-62.02 \pm 0.10$ & $1980 \pm 0.00$ \\
\hline & $E$ & $-107.32 \pm 0.01$ & $-80.54 \pm 0.09$ & $1830 \pm 0.00$ \\
\hline
\end{tabular}

Table 2. Mean venous limb pressure (P1), mean venous reservoir pressure (P2), and arterial line flow (forward flow) measured at baseline flow of 1500, 2000, and $2500 \mathrm{~mL} / \mathrm{min}$ with vacuum off and increments of vacuum-assisted venous drainage levels (-20, -40, -60 , and -80; conditions A to E) keeping the purge line open.

\begin{tabular}{|c|c|c|c|c|c|}
\hline Adjusted flow & Condition & $\begin{array}{l}\text { P1 venous limb } \\
\text { pressure }(\mathrm{mmHg})\end{array}$ & $\begin{array}{c}\text { P2 venous } \\
\text { reservoir pressure } \\
(\mathrm{mmHg})\end{array}$ & $\begin{array}{c}\text { Arterial flow (mL/ } \\
\text { min) }\end{array}$ & $\begin{array}{l}\text { Deviated flow } \\
\text { (mL/min) }\end{array}$ \\
\hline \multirow{5}{*}{$1500 \mathrm{ml} / \mathrm{min}$} & A & $-29.43 \pm 0.11$ & $-0.73 \pm 0.00$ & $1230 \pm 0.00$ & $430 \pm 0.00$ \\
\hline & $\mathrm{B}$ & $-53.15 \pm 0.25$ & $-22.52 \pm 0.27$ & $960 \pm 0.00$ & $490 \pm 0.00$ \\
\hline & C & $-69.17 \pm 0.23$ & $-37.80 \pm 0.18$ & $740 \pm 0.00$ & $550 \pm 0.00$ \\
\hline & D & $-92.47 \pm 0.40$ & $-59.48 \pm 0.53$ & $440 \pm 0.00$ & $610 \pm 0.00$ \\
\hline & $E$ & $-112.28 \pm 0.17$ & $-82.04 \pm 0.15$ & $160 \pm 0.00$ & $650 \pm 0.00$ \\
\hline \multirow{5}{*}{$2000 \mathrm{ml} / \mathrm{min}$} & A & $-28.29 \pm 0.30$ & $-1.22 \pm 0.01$ & $1700 \pm 0.01$ & $490 \pm 0.01$ \\
\hline & $\mathrm{B}$ & $-46.87 \pm 0.11$ & $-18.62 \pm 0.34$ & $1480 \pm 0.01$ & $560 \pm 0.01$ \\
\hline & C & $-67.49 \pm 0.40$ & $-38.63 \pm 0.11$ & $1640 \pm 0.01$ & $580 \pm 0.01$ \\
\hline & $\mathrm{D}$ & $-92.42 \pm 0.35$ & $-62.62 \pm 0.12$ & $1040 \pm 0.00$ & $610 \pm 0.00$ \\
\hline & E & $-111,79 \pm 0.17$ & $-81.37 \pm 0.13$ & $770 \pm 0.01$ & $660 \pm 0.01$ \\
\hline \multirow{5}{*}{$2500 \mathrm{ml} / \mathrm{min}$} & A & $-29.43 \pm 0.11$ & $-29.43 \pm 0.11$ & $1230 \pm 0.00$ & $560 \pm 0.00$ \\
\hline & B & $-53.15 \pm 0.25$ & $-53.15 \pm 0.25$ & $960 \pm 0.00$ & $590 \pm 0.01$ \\
\hline & C & $-69.17 \pm 0.23$ & $-69.17 \pm 0.23$ & $740 \pm 0.00$ & $610 \pm 0.01$ \\
\hline & D & $-92.47 \pm 0.40$ & $-92.47 \pm 0.40$ & $440 \pm 0.00$ & $690 \pm 0.00$ \\
\hline & E & $-112.28 \pm 0.17$ & $-112.28 \pm 0.17$ & $160 \pm 0.00$ & $710 \pm 0.00$ \\
\hline
\end{tabular}




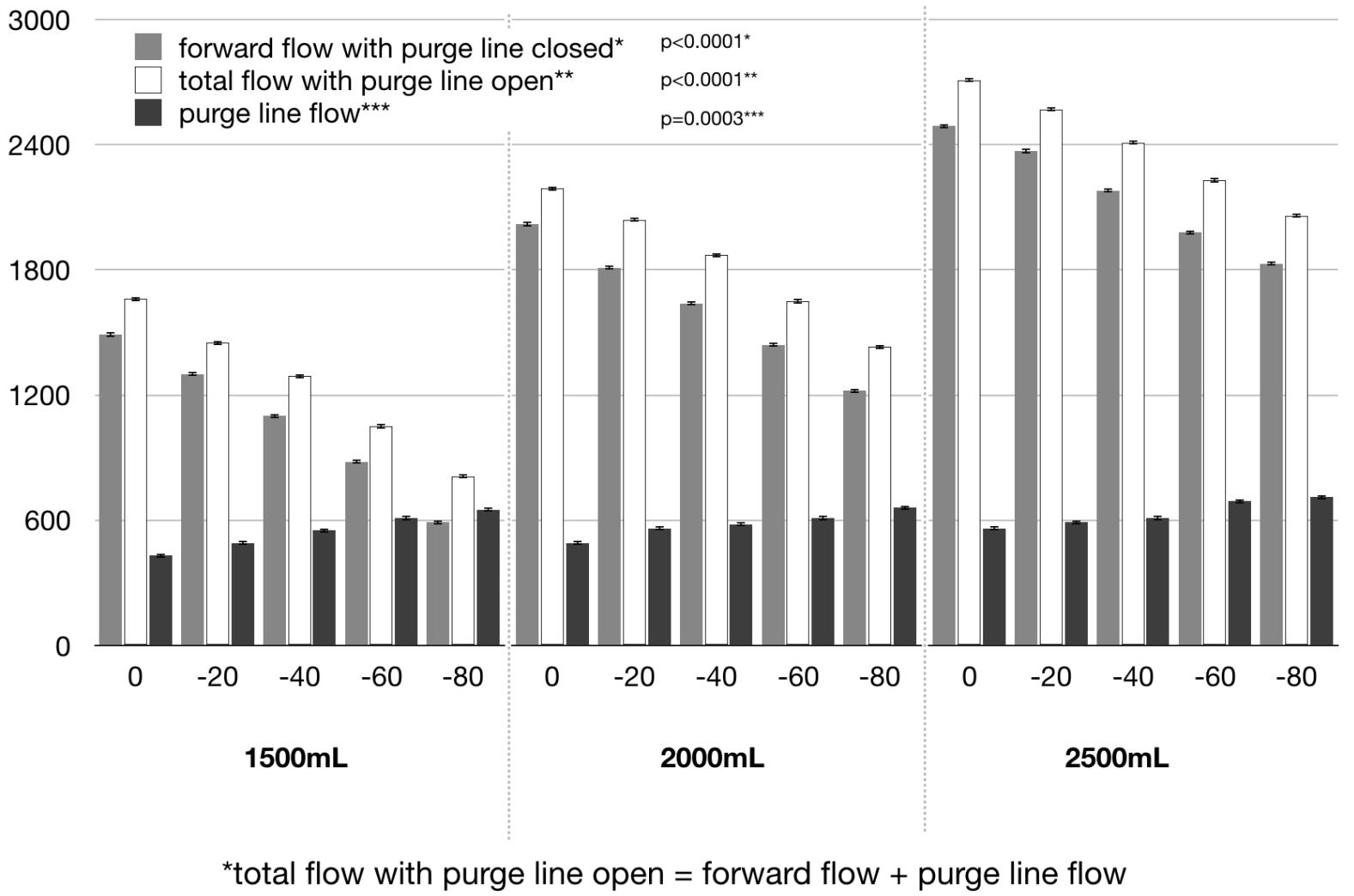

Fig. 2 - The total (post-arterial filter flow + deviated flow through the purge line) forward flow increases when purge line is open as a compensation to the stealing flow in this situation.

In the literature, controversy persists regarding the advantages and preferences of using RP vs. CP for generating arterial flow ${ }^{[18]}$. However, the lack of clarity of clinical benefits of the more expensive $\mathrm{CP}$ is exemplified in the significant disparity in the choice of main arterial pump in North America (RP $=51 \%, C P=49 \%)$, AustraliaNew Zealand (RP $=70 \%, C P=30 \%)$, and Europe $(R P=90 \%, C P$ $=10 \%)^{[5,19]}$. A recent survey in Brazil[ ${ }^{[9]}$ showed that CPs are used as the main arterial pump in cardiac surgeries, including pediatric and neonatal patients, in $60 \%$ of cardiac centers. There have been conflicting results reporting the effects of the two pump types on transfusions, platelet counts, plasma-free hemoglobin, postoperative mediastinal bleeding, and clinical outcomes ${ }^{[5-7]}$. Studies comparing CP and RP generally have small sample size with limited statistical power to detect differences in outcome measures. A meta-analysis of randomized controlled trials has been performed to combine the clinical outcome data and synthesize the evidence comparing RP and CP as the main arterial pump in adult cardiac surgery ${ }^{[8]}$. No differences in postoperative blood loss, hospital length of stay, intensive care unit length of stay, mortality, or device mishap-related morbidity or hematologic variables were found ${ }^{[8]}$. These findings suggest that RPs and CPs can both be used with comparable outcomes.

One major concern is that CP is afterload-dependent. An increase in downstream resistance decreases forward flow delivered to the patient if no adjustment is made to the set RPM ${ }^{[20]}$. Furthermore, a CP is preload-dependent and any modification in the pressure at the CP inflow will impact pump output, as shown in our in vitro experiment. Therefore, effective forward flow with the use of a CP for the arterial pump is impacted by both inflow and outflow conditions.

Literature has shown that augmented venous return techniques may help to introduce GME into the patient undergoing $\mathrm{CPB}^{[15,16,21]}$. Although many other potential causes for gaseous emboli during CPB have been identified (venous reservoir with low level of blood, cavitation, etc.), the creation of a negative pressure in the venous line facilitates entrainment of air around the venous cannula, possibly increasing GME[21]. LaPietra et al. ${ }^{[22]}$ compared the potential for GME formation and transmission with the use of augmented venous return systems and the GME handling capabilities of various clinical augmented venous return CPB circuits. Significant increases were associated with increasing negative vacuum pressure $(P<0.001)$ and use of an arterial RP $(P=0.01)$. They concluded that when assisted venous drainage techniques are used, a CP as the main arterial pump enhances the removal of significant GME that may occur even in the presence of a standard arterial line filter ${ }^{[22]}$. Despite this potential advantage of using CP and VAVD, we did not assess GME in our experiment. 
I - forward flow with purge line closed
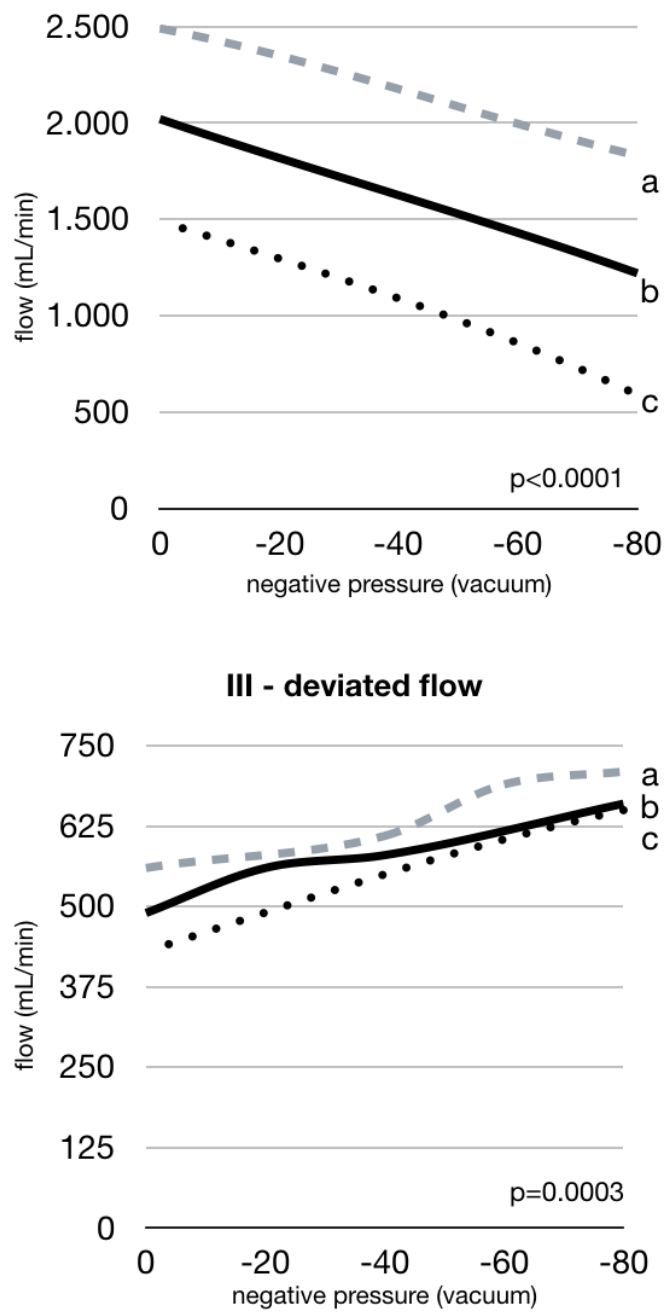
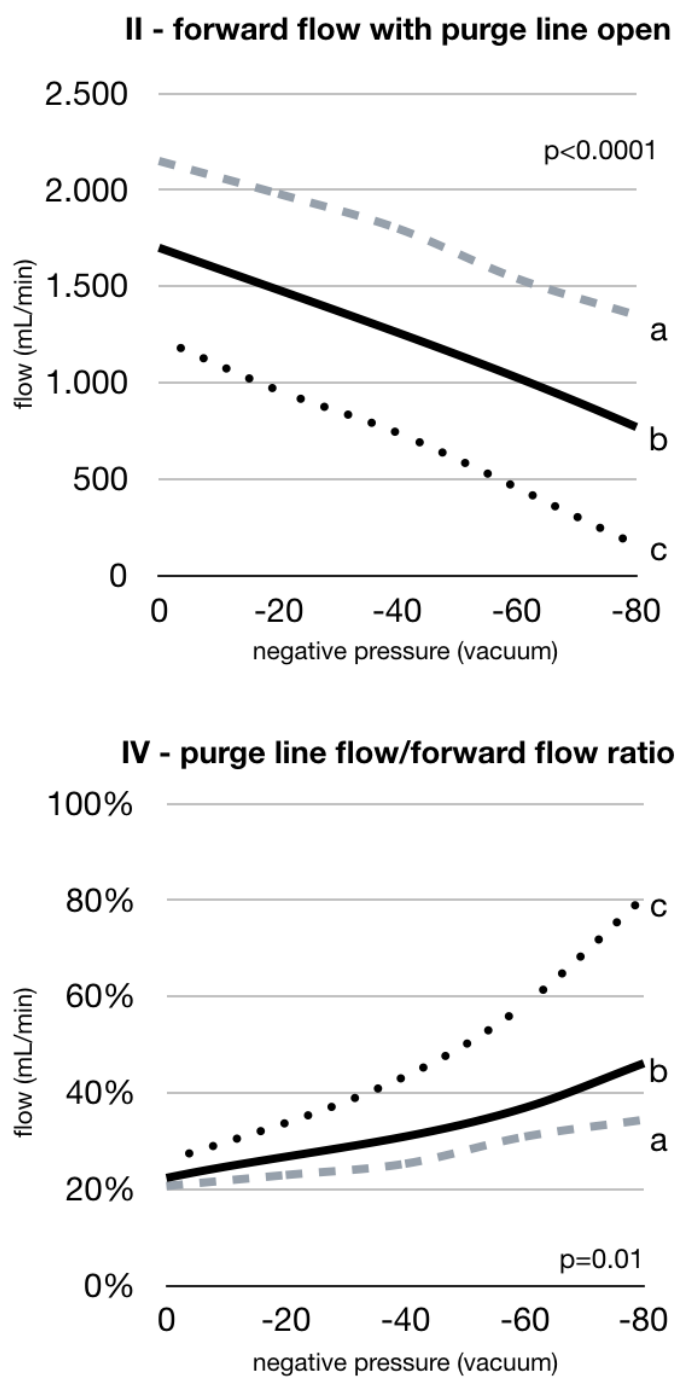

Fig. 3 - Influence of the negative pressure applied to venous reservoir and to the initial forward flow (arterial line flow) of $2500 \mathrm{~mL} / \mathrm{min}$ (a), $2000 \mathrm{~mL} / \mathrm{min}$ (b), and $1500 \mathrm{~mL} / \mathrm{min}$ (c); with the purge line closed (I) and purge line open (II); to the deviated flow (III); and percentage of purge line flow/forward flow ratio (IV).

The use of combined methods, CP and VAVD, is safe, but it requires caution and an adequate arterial flow to help ensure effective forward flow and end-organ perfusion.

It is worth noting that the purge line flow is limited by the size of the purge line tubing. This explains the findings that similar purge line flows obtained at increasing CP flows. Consequently, purge line flow may have a greater impact when lower flows are required.

This study has the limitations of an in vitro experiment. In vivo studies may be needed to evaluate the impacts of these findings on clinical outcomes.

\section{CONCLUSION}

The use of VAVD reduces the effective arterial flow when a CP is used in the arterial position and this flow reduction is amplified when an external arterial line filter is in use. All perfusion systems should utilize an independent flow probe on the arterial limb, and this is especially essential with the use of a centrifugal arterial pump head, with and without an external arterial line filter. The use of a flow probe, as shown in our simulated pediatric bypass circuit, will help ensure effective forward flow and adequate systemic perfusion during CPB.

Funding: This work had financial support from the State of São Paulo Research Foundation - FAPESP (2012/50283-6), the National Council for Scientific and Research Development - CNPq/MS/ SCTIE/DECIT (467270/2014-7), and FINEP (01-14-0177-00).

\section{No conflict of interest.}




\section{Authors' roles \& responsibilities}

DPG Substantial contributions to the conception or design of the work; or the acquisition, analysis, or interpretation of data for the work; drafting the work or revising it critically for important intellectual content; final approval of the version to be published;

LFC Substantial contributions to the conception or design of the work; or the acquisition, analysis, or interpretation of data for the work; drafting the work or revising it critically for important intellectual content; final approval of the version to be published;

GM Drafting the work or revising it critically for important intellectual content; final approval of the version to be published

LPC Substantial contributions to the conception or design of the work; or the acquisition, analysis, or interpretation of data for the work; drafting the work or revising it critically for important intellectual content; final approval of the version to be published

VCP Substantial contributions to the conception or design of the work; or the acquisition, analysis, or interpretation of data for the work

AVCXC Substantial contributions to the conception or design of the work; or the acquisition, analysis, or interpretation of data for the work

MHCM Substantial contributions to the conception or design of the work; or the acquisition, analysis, or interpretation of data for the work

PSC Substantial contributions to the conception or design of the work; or the acquisition, analysis, or interpretation of data for the work

MBJ Final approval of the version to be published

IC Substantial contributions to the conception or design of the work; or the acquisition, analysis, or interpretation of data for the work; drafting the work or revising it critically for important intellectual content; final approval of the version to be published;

FBJ Final approval of the version to be published

\section{REFERENCES}

1. Corno AF. Systemic venous drainage: can we help Newton? Eur J Cardiothorac Surg. 2007;31(6):1044-51. doi:10.1016/j.ejcts.2007.01.066.

2. Caneo LF, Matte GS, Guimarães DP, Viotto G, Mazzeto M, Cestari l, et al. Functional performance of different venous limb options in simulated neonatal/pediatric cardiopulmonary bypass circuits. Braz J Cardiovasc Surg. 2018;33(3):224-32. doi:10.21470/1678-9741-2018-0074.

3. Matte GM. Perfusion for congenital heart surgery: notes on cardiopulmonary bypass for a complex patient population: New Jersey: Wiley Blackwell; 2015. 208p.

4. Jakob HG, Hafner G, Thelemann C, Stürer A, Prellwitz W, Oelert H. Routine extracorporeal circulation with a centrifugal or roller pump. ASAIO Trans. 1991;37(3):M487-9.

5. Klein M, Dauben HP, Schulte HD, Gams E. Centrifugal pumping during routine open heart surgery improves clinical outcome. Artif Organs.
1998;22(4):326-36. doi:10.1046/j.1525-1594.1998.06051.x

6. Triveldi U, Timberlake N, Bennywith O, Chambers D, Venn G, Newman $\mathrm{S}$. The impact of centrifugal and roller pump in CABG on microembolic and neuropsychological outcomes. Perfusion. 1997:12:67.

7. DeBois WJ, Brennan R, Wein E, Isom OW, Gold JP. Centrifugal pumping: the patient outcome benefits following coronary artery bypass surgery. J Extra Corpor Technol. 1995;27(2):77-80.

8. Saczkowski R, Maklin M, Mesana T, Boodhwani M, Ruel M. Centrifugal pump and roller pump in adult cardiac surgery: a meta-analysis of randomized controlled trials. Artif Organs. 2012;36(8):668-76. doi:10.1111/j.1525-1594.2012.01497.x.

9. Jatene MB, Caneo LF. Avaliação das práticas em perfusão pediátrica [Internet]. São Paulo:[publisher unknown), 2018 [cited 2019 Nov 16]. Available from: https://pt.surveymonkey.com/r/9BSYX2W

10. Jegger D, Tevaearai HT, Mueller XM, Horisberger J, von Segesser LK. Limitations using the vacuum-assist venous drainage technique during cardiopulmonary bypass procedures. J Extra Corpor Technol. 2003:35(3):207-11

11. Vida VL, Bhattarai A, Speggiorin S, Zanella F, Stellin G. Effect of vacuum on venous drainage: an experimental evaluation on pediatric venous cannulas and tubing systems. JNMA J Nepal Med Assoc. 2014;52(196):960-6. doi:10.31729/jnma.2794.

12. Gambino R, Searles B, Darling EM. Vacuum-assisted venous drainage: a 2014 safety survey. J Extra Corpor Technol. 2015;47(3):160-6.

13. Carvalho Filho EB, Marson FA, Costa LN, Antunes N. Vacuum-assisted drainage in cardiopulmonary bypass: advantages and disadvantages. Rev Bras Cir Cardiovasc. 2014;29(2):266-71. doi:10.5935/1678-9741.20140029.

14. Shade BC, Melchior RW, Fisher DR, High R, Mascio CE, Rosenthal TM, et al. Comparison of three infant venous reservoirs with vacuum-assisted venous drainage during varying levels of cardiotomy suction. Perfusion. 2019:267659119850344. doi:10.1177/0267659119850344.

15. Wang S, Undar A. Vacuum-assisted venous drainage and gaseous microemboli in cardiopulmonary bypass. J Extra Corpor Technol. 2008:40(4):249-56.

16. Sathianathan S, Nasir R, Wang S, Kunselman AR, Ündar A. In vitro evaluation of capiox FX05 and RX05 oxygenators in neonatal cardiopulmonary bypass circuits with varying venous reservoir and vacuum-assisted venous drainage levels. Artif Organs. 2018. doi:10.1111/aor.13404.

17. Caneo LF, Matte G, Groom R, Neirotti RA, Pêgo-Fernandes PM, Mejia JAC, et al. The Brazilian society for cardiovascular surgery (SBCCV) and Brazilian society for extracorporeal circulation (SBCEC) standards and guidelines for perfusion practice. Braz J Cardiovasc Surg. 2019;34(2):23960. doi:10.21470/1678-9741-2018-0347.

18. Murphy GS, Hessel EA 2nd, Groom RC. Optimal perfusion during cardiopulmonary bypass: an evidence-based approach. Anesth Analg. 2009;108(5):1394-417. doi:10.1213/ane.0b013e3181875e2e.

19. Baker RA, Willcox TW. Australian and New Zealand perfusion survey: equipment and monitoring. J Extra Corpor Technol. 2006;38(3):220-9.

20. Hessel EA, Hill AG. Circuitry and cannulation techniques. In: Gravlee GP, Davis RF, Kurusz M, Utley JR. Cardiopulmonary bypass: principles and practices. 4th ed. New York: Lippincott Williams \&Wilkins; 2015. p 19-93.

21. Willcox TW, Mitchell SJ, Gorman DF. Venous air in the bypass circuit: a source of arterial line emboli exacerbated by vacuum-assisted drainage. Ann Thorac Surg. 1999;68(4):1285-9. doi:10.1016/s0003-4975(99)00721-3.

22. Lapietra A, Grossi EA, Pua BB, Esposito RA, Galloway AC, Derivaux CC, et al. Assisted venous drainage presents the risk of undetected air microembolism. J Thorac Cardiovasc Surg. 2000;120(5):856-62. doi:10.1067/mtc.2000.110183. 